\title{
Why the 'devious defecator' case is a landmark for US genetic- privacy law
}

\begin{abstract}
Nature explores the impact of the first US court decision over how employers use genetic information.
\end{abstract}
Natasha Gilbert

25 June 2015

A US company is the first to face penalties under the Genetic Information Nondiscrimination Act (GINA), a law that protects the privacy of genetic information. On 22 June, a federal court jury in Georgia awarded US\$2.25 million to two men whose employer tested their DNA, seeking to identify who had repeatedly left faeces in one of its warehouses.

The firm, Atlas Logistics Group Retail Services, a grocery distributor in Atlanta, Georgia, asked employees Jack Lowe and Dennis Reynolds to give cheek swabs in 2012. Atlas sent their DNA to a lab for genetic comparison with the offending faecal matter. The tests showed that Lowe and Reynolds' DNA was not a match.

In 2013, the workers sued Atlas. The case, nicknamed the 'mystery of the devious defecator' by US district court judge Amy Totenberg, is the first brought under GINA to go to trial. Here, Nature explains why the ruling matters.

\section{Why is a law such as GINA necessary?}

People are afraid that their DNA could be used against them by employers or insurance companies, says Amanda Farahany, the lawyer who represents the two employees. GINA, which was enacted in 2008, protects people against the misuse of their genetic information. Farahany says that its goal is to ensure that people are more comfortable "turning over their DNA to help advances in health care".

\section{What does the law say?}

The law prohibits employers in the United States from requesting genetic information or from using it to make employment decisions, including hiring, firing and promotions. It also prevents US health-insurance companies from using such information to decide whether a person is eligible for coverage.

The law does include limited exemptions, however. Forensic laboratories can ask workers for their DNA to check that employees' genetic material does not contaminate the genetic samples that they analyse.

\section{Why is this case significant?}

This is the first case under GINA that has gone to trial.

Atlas's lawyers argued that GINA did not apply in this instance, because the company used Lowe and Reynolds' genetic samples in an attempt to identify the 'devious defecator' — not to learn about either man's medical profile. The jury rejected the argument and awarded the employees $\$ 2.25$ million for their suffering.

"This is an application of the law that no one thought of in a million years," says John Conley, a law professor at the University of North Carolina in Chapel Hill and editor of Genomics Law Report. "But the ruling is not controversial. You can't use genetic testing for dismissal purposes."

\section{Are similar legal challenges pending?}

As more people become aware of GINA, it is being invoked more frequently in legal matters. In 2010, the US Equal Employment Opportunity Commission (EEOC), a government agency that enforces anti-discrimination laws, filed 201 cases that cited GINA. In 2014 , the number of such cases rose to 333 .

One of the first legal challenges under GINA was filed in 2010 by a Connecticut woman who argued that she had been fired because she had an increased risk of breast cancer. According to reports, Pamela Fink tested positive in 2010 for mutations in the BRCA2 gene that are associated with increased cancer risk. After undergoing preventive breast surgery and reconstruction, she was dismissed from her job and later filed a discrimination charge. 
The case has since been resolved, according to Fink's attorney, who declined further comment.

\section{Is the law working?}

Employers and insurance companies are generally not abusing people's genetic information in the way that GINA set out to guard against, says Conley. "The law seems to be working," he adds.

Nevertheless, "people still fear the invasion of their genetic privacy," Farahany says. "Society is trying to working out how to handle this." But this ruling makes a clear statement, she adds: employers cannot use genetic information to make employment decisions under any circumstances.

Nature | doi:10.1038/nature.2015.17857 